\title{
Editorial Expression of Concern: Implantation of a Novel Allogeneic Mesenchymal Precursor Cell Type in Patients with Ischemic Cardiomyopathy Undergoing Coronary Artery Bypass Grafting: an Open Label Phase IIa Trial
}

\author{
Kyriakos Anastasiadis $^{1}$ - Polychronis Antonitsis ${ }^{1} \cdot$ Stephen Westaby $^{2} \cdot$ Ajan Reginald $^{3} \cdot$ Sabena Sultan $^{3}$. \\ Argirios Doumas $^{4} \cdot$ George Efthimiadis $^{5} \cdot$ Martin John Evans $^{3}$
}

Published online: 19 October 2020

(C) Springer Science+Business Media, LLC, part of Springer Nature 2020

\section{Correction to: J. of Cardiovasc. Trans. Res. https://doi.org/10.1007/s12265-016-9686-0}

The Editor-in-Chief of the Journal of Cardiovascular Translational Research is issuing an Editorial Expression of Concern on this article [1].

Following an investigation into a number of concerns raised in relation to this article after publication, the journal has found that the study did not receive all necessary approvals from regulatory and ethical bodies. While it has been confirmed that the study received approval from both the AHEPA University Hospital IRB and the IRB of the School of Medicine, Aristotle University of Thessaloniki,

The online version of the original article can be found at https://doi.org/ 10.1007/s12265-016-9686-0

Polychronis Antonitsis

antonits@auth.gr

1 Cardiothoracic Department, AHEPA University Hospital, S. Kyriakidi 1, 54636 Thessaloniki, Greece

2 The John Radcliffe Hospital, Oxford University Hospitals, Headington, Oxford, UK

3 Cell Therapy Ltd., Celixir House, Innovation Way, Stratford upon Avon, UK

4 Department of Nuclear Medicine, AHEPA University Hospital, Aristotle University of Thessaloniki, Thessaloniki, Greece

5 First Cardiology Department, AHEPA University Hospital, Thessaloniki, Greece our investigation has found that advance approvals were not obtained from the National Ethics Committee nor the National Organizations for Medicines, as required for clinical trials conducted in Greece. This Expression of Concern does not comment on whether the research followed applicable ethical standards.

Additionally, during the investigation, the authors clarified the following about the methods: left ventricular ejection fraction (LVEF) at baseline was manually corrected by the independent referring cardiologists before inclusion in the study. After reviewing the raw data, discrepancies can be found between the estimated and calculated LVEF data. As this raises questions about the accuracy of the method to determine whether patients met the inclusion criterion of an LVEF of less than $40 \%$, the readers are advised to interpret the findings related to the baseline LVEF data with caution.

The authors would also like to correct the following details:

Methods - culture of iMP

The manuscript states that "the iMP cells used in this study were prepared under GMP/ISO 9001 conditions."

To avoid confusion, the authors would like to correct this to "the iMP cells used in the study were prepared under ISO 9001 and ISO 15189 conditions."

Authors' Affiliations

Dr Sabena Sultan, Ajan Reginald and Prof. Sir Martin Evans correct affiliation were with Cell Therapy Ltd., Celixir House, Innovation Way, Stratford upon Avon 


\section{Conflicts of Interest}

- Stephen Westaby wishes to declare he was issued options in Cell Therapy Ltd. in 2012, which were later converted into shares.

- While the authors Ajan Reginald, Sir Martin John Evans and Sabena Sultan declared that they held shares in Cell Therapy Ltd., they would also like to declare their affiliation with Cell Therapy Ltd. at the time of submission.

Authors Polychronis Antonitsis, Kyriakos Anastasiadis, Argirios Doumas and Stephen Westaby agree to this Editorial Expression of Concern. Authors Ajan Reginald, Martin John Evans and Sabena Sultan disagree with this
Editorial Expression of Concern. Author George Efthimiadis has not responded to the editor about this Editorial Expression of Concern.

[1] Mesenchymal Precursor Cell Type in Patients with Ischemic Cardiomyopathy Undergoing Coronary Artery Bypass Grafting: an Open Label Phase IIa Trial. J. of Cardiovasc. Trans. Res. 9, 202-213 (2016). https://doi.org/ 10.1007/s12265-016-9686-0

Publisher's Note Springer Nature remains neutral with regard to jurisdictional claims in published maps and institutional affiliations. 